\title{
A case of single ventricular heart, pulmonary atresia, patent ductus arteriosus, major aortopulmonary collateral arteries
}

\author{
Rema V. Nair ${ }^{1}$, Velayudhan Nair ${ }^{2}$, Mookambika R. V. ${ }^{3}$, Mohandas Rao K. G. ${ }^{4 *}$, Somayaji S. N. ${ }^{4}$ \\ ${ }^{1}$ Department of Obstretics and Gynacology, Mookambika Institute of Medical Sciences, Kulasekaram, Tamil Nadu, India. ${ }^{2}$ Department \\ of Surgery, Mookambika Institute of Medical Sciences, Kulasekaram, Tamil Nadu, India. ${ }^{3}$ Department of Medicine, Mookambika Institute \\ of Medical Sciences, Kulasekaram, Tamil Nadu, India. ${ }^{4}$ Department of Anatomy, Melaka Manipal Medical College, Manipal University, \\ Manipal, 576 104, India
}

\section{A B S T R A C T}

We report a case of multiple congenital anomalies in a female newborn infant, born to the mother from a hill tribe. The Doppler echocardiography of the baby showed large atrial septal defect amounting to single atrium, atretic left atrioventricular valve, large single right sided ventricle, aorta shifted to the left arising from single ventricle and diminutive hypoplastic left ventricle. Right atrioventricular valve was normal forming single inlet into the ventricle. Pulmonary artery was small and hypoplastic and no antegrade flow was observed in it. The patient was diagnosed as having single ventricle, pulmonary atresia, patent ductus arteriosus (PDA) and major aortopulmonary collateral artery (MAPCA).

Key Words: Congenital anomalies, Single atrium, Single ventricle, Major aortopulmonary collateral artery, Patent ductus arteriosus

\section{INTRODUCTION}

The malformation of the heart or the large blood vessels associated with it, affecting the various parts or functions of heart are considered as congenital heart diseases (CHDs). ${ }^{1}$ About $30 \%$ of the total congenital abnormalities are reported to be CHDs. ${ }^{2}$ The majority of CHD cases occur as isolated malformations, but about $33 \%$ of them reported to have associated anomalies. ${ }^{3}$ Some of the frequently observed CHDs include atrial septal defects $(6.4 / 10,000)$, ventricular septal defects $(12 / 10,000)$, tetralogy of Fallot $(9.6 / 10,000)$, aorta originating from right ventricle $(4.8 / 10,000)$, Patent ductus arteriosus $(8 / 10,000)$, and pulmonary atresia $(4 / 10,000) .{ }^{4}$ Some of the rarely observed CHDs are persistent truncus arteriosus, tricuspid atresia, hypoplastic left heart syndrome, double outlet right ventricle and single ventricle. ${ }^{1}$

\section{CLINICAL EXAMINATIONS AND INVESTIGATIONS}

At Department of Obstetrics and Gynecology, Mookambika Institute of Medical Sciences, Kulasekaram,
Tamil Nadu, India, a female baby was born with multiple congenital anomalies to a mother who is from hill tribe.

The Doppler echocardiography showed large atrial septal defect amounting to single atrium, atretic left atrioventricular valve, large single right sided ventricle, aorta shifted to the left arising from single ventricle and diminutive hypoplastic left ventricle. Right atrioventricular valve was normal forming single inlet into the ventricle. Pulmonary artery was small and hypoplastic and no antegrade flow was observed. The baby was diagnosed as having single ventricle, pulmonary atresia, patent ductus arteriosus (PDA) and major aortopulmonary collateral artery (MAPCA) (Figure 1).

\section{DISCUSSION}

Prevalence of CHDs at the global level is reported to be ranging from 1.01 (Egypt) to 17.5 (Central Australia) per 1000 live births. ${ }^{1}$ A study conducted in the region of Mysore (a city in South India), has revealed the frequency of CHDs as 10.65 per 1000 live births which is lower 


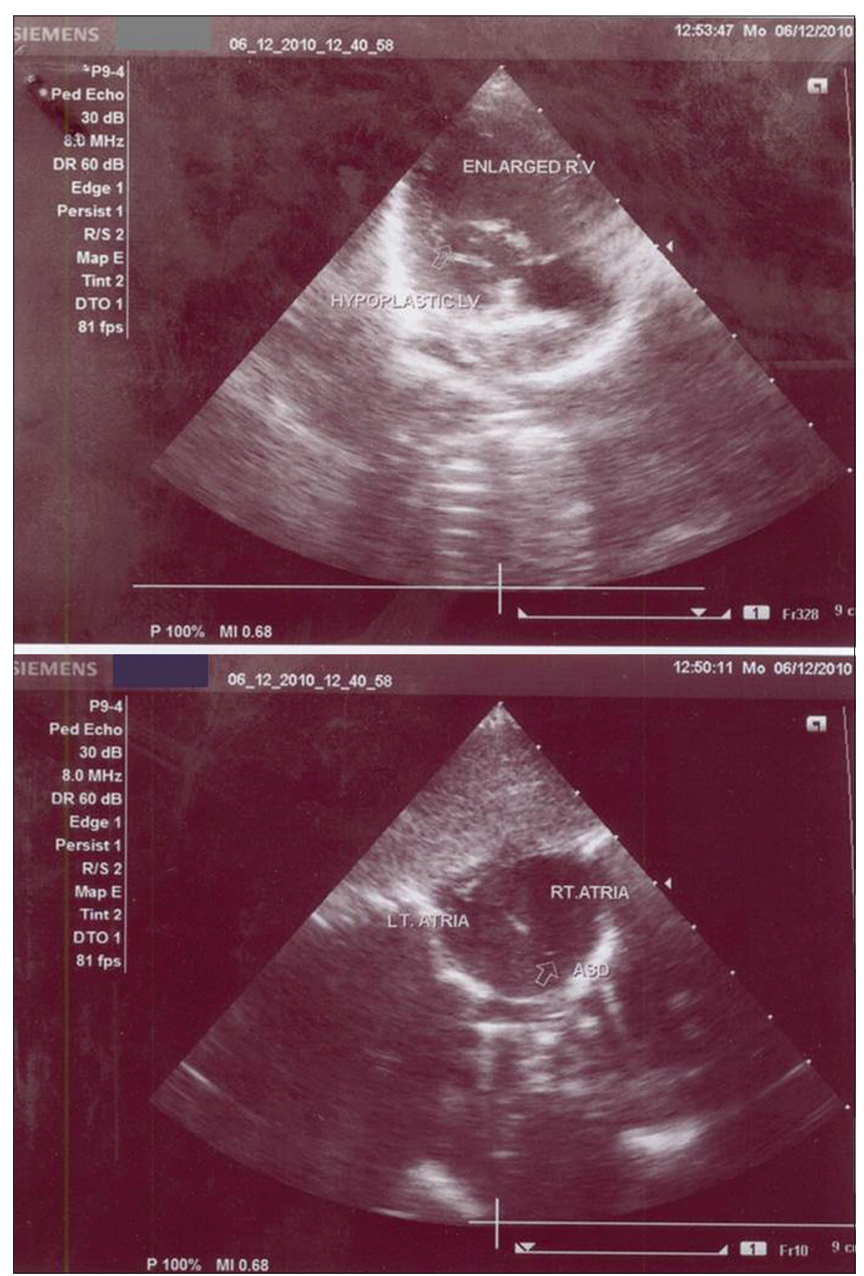

Figure 1: Echocardiograms showing enlarged right ventricle (enlarged RV) and hypoplastic left ventricle (hypoplastic LV shown with small arrow). LT.ATRIA- left atrium, RT.Atrium- right atrium, ASD- atrial septal defect

compared to an earlier report from South India (25.6 per 1000 live births). ${ }^{1,5}$ Ventricular septal defects are found to be the most prevalent type of defects in most of the studies on Indian population. ${ }^{1}$ The frequency of other rare types of CHDs namely atrioventricular septal defects, pulmonary stenosis, single ventricle, hypoplastc left heart syndrome has been reported to be less in India when compared to the data from western population. ${ }^{1}$ It can be noted here that most of the congenital heart defects which are considered to be less frequent among Indian population, like single ventricle, pulmonary atresia, atrial septal defect, hypoplastic left ventricle have been observed in the present case along with exomphalos.

It has been reported that the most commonly observed CHDs are ventricular septal defects with pulmonary atresia. ${ }^{6}$ Ugurlucan et al. have reported a case of ventricular septal defect, pulmonary atresia, non-confluent cardiac anomalies, pulmonary arteries and bilateral patent ductus arteriosi. ${ }^{7}$ Similar case of pulmonary atresia, ventricular septal defect, and major aortopulmonary collateral arteries has been reported in a 10 month old Thai baby. ${ }^{8}$ In the present case, though the patient showed other associated cardiac anomalies, pulmonary atresia, patent ductus arteriosus and major aortopulmonary collateral arteries are considered as functionally significant. When there is such multiple congenital cardiac anomalies, aortic arch anomalies like patency of ductus arteriosus and major aortopulmonary collateral arteries are common and vital, otherwise death is inevitable. ${ }^{7}$ Pulmonary atresia with intact ventricular septum causing sudden death due to myocardial ischaemia is well-established. ${ }^{9}$ However, in the present case, though there was no ventricular septal defect, the patient survived, may be due the origin of aorta from the single right ventricle and major aortopulmonary collateral arteries.

Though the formation of major aortopulmonary collateral vessels is essential for the survival of patients with pulmonary atresia and ventricular septal defects, they pose a unique and challenging problem at the time of surgical repair. Such repairs involve the closure of ventricular septal defect, relief of right ventricular outflow tract obstruction, maintenance of pulmonary valve competency when possible, and establishment of laminar pulmonary blood flow to all segments of the pulmonary bed. ${ }^{10}$ In addition, it has been reported that the presence of foetal major aortopulmonary collateral arteries is associated with adverse outcome, therefore early diagnosis is essential. ${ }^{11}$ In patients with pulmonary atresia and major aortopulmonary collateral arteries such as one reported in the present case, different surgical procedures are used as treatment. Rehabilitation of hypoplastic native pulmonary arteries by a neonatal shunting regimen, without major aortopulmonary collateral artery translocation has been reported to give good results with excellent early survival. ${ }^{12}$ According to Fang et al., the surgical strategy for patients with pulmonary atresia, ventricular septal defects and major aortopulmonary collateral arteries, depends mainly on the anatomical features of native pulmonary arteries, confluent pulmonary arteries and major aortopulmonary collateral arteries. ${ }^{13}$ Though the pulmonary artery rehabilitation allows complete repair in the majority of patients with pulmonary atresia, hypoplastic pulmonary arteries, and major aortopulmonary collaterals, long-term management often requires pursuit of the rehabilitation process. ${ }^{14}$ A two-stage complete repair strategy has been proposed by Mei et al. and has been reported to be well-tolerated and effective with good outcome, offering an alternative surgical approach in the treatment of patients with pulmonary atresia and major aortopulmonary collateral arteries. ${ }^{15}$ 


\section{CONCLUSION}

Case of single ventricle, pulmonary atresia, interatrial septal defect, patent ductus arteriosus and major aortopulmonary collateral arteries is rare. It is essential for the pediatricians, gynecologists, cardiologists and pediatric surgeons to be aware of incidents of such cases.

\section{REFERENCES}

1. Smitha R, Karat SC, Narayanappa D, Krishnamurthy B, Prasanth SN and Ramachandra NB. Prevalence of congenital heart diseases in Mysore. Indian Journal of Human Genetics 2006; 12(1):11-16.

2. Noonan JA and Ehmke DA. Associated non cardiac malformations in children with congenital heart disease. J Pediatr 1963; 63:468-471.

3. Frias JL. Genetic issues of congenital heart disease. In: Gessner IH, Victrorica BE, (editors) Pediatric cardiology. Saunders: Philadelphia; 1993. p. 237-242.

4. Sadler TW. Langman's medical embryology. $9^{\text {th }}$ edition Lippincott Williams and Wilkins. Philadelphia Pennsylvania USA. 2004; 223-273, 304-313.

5. Gupta S, Puri RK, Indira OC and Datta SP. Morbidity in children under 14 in South India. Indian Pediat 1968; 5:485-497.

6. Taggart NW, Shaughnessy WJ, Stans AA, Mclntosh AL and Driscoll DJ. Outcomes of spinal fusion in children with congenital heart disease. J Pediatr Orthop 2010; 30(7):670-675.

7. Ugurlucan M, Sayin OA, Dayioglu E and Tireli E. Bilateral PDA in a Patient with VSD and Pulmonary Atresia. J Card Surg 2011; 26(1):107-110.

8. Khositseth A, Siripornpitak $S$ and Pornkul R. Pulmonary atresia and ventricular septal defect with collaterals to right lung associated with anomalous left pulmonary artery from the ascending aorta. Pediatr Radiol 2010; 40 (1):72-76.

9. Patel AR, Goldberg D and Shah M. Paroxysmal complete atrioventricular block in a patient with pulmonary atresia and intact ventricular septum. Cardiol Young 2011; 21(1):94-96.

10. Antonetti I, Lorch D, Coe B, Maxey TS, Nallamshetty L, Dadlani $\mathrm{GH}$, et al. Unrepaired Tetralogy of Fallot with Major Aortopulmonary Collateral Arteries in an Adult Patient. Congenit Heart Dis 2013; 8(1):E24-30. doi: 10.1111/j.17470803.2011.00598.x. Epub 2011 Dec 18.

11. Moszura T, Janiak $\mathrm{K}$, Respondek-Liberska $\mathrm{M}$, MazurekKula A, Dryżek P, Moll J, et al. A Prenatal diagnosis of major aortopulmonary collateral arteries. Kardiol Pol 2011; 69(2):146-151.

12. Liava'a M, Brizard CP, Konstantinov IE, Robertson $T$, Cheung MM, Weintraub R, et al. Pulmonary atresia, ventricular septal defect, and major aortopulmonary collaterals: neonatal pulmonary artery rehabilitation without unifocalization. Ann Thorac Surg 2012; 93(1):185-191.

13. Fang MH, Wang HS, Wang ZW, Zhu HY, Song HC and Zhang NB. The anatomy features and surgical significance of the pulmonary circuits of pulmonary atresia with ventricular septal defect and major aortopulmonary collateral arteries. Zhonghua Wai Ke Za Zhi 201; 49(5):396-399.

14. Dragulescu A, Kammache I, Fouilloux V, Amedro P, Métras D, Kreitmann B, et al. Long-term results of pulmonary artery rehabilitation in patients with pulmonary atresia, ventricular septal defect, pulmonary artery hypoplasia, and major aortopulmonary collaterals. J Thorac Cardiovasc Surg 2011; 142(6):1374-1380.

15. Mei J, Ding FB, Zhu JQ, Bao CR, Xie X and Zhang YJ. A novel two-stage complete repair method for pulmonary atresia with ventricular septal defect and major aortopulmonary collateral arteries. Chin Med J (Engl) 2010; 123(3):259-264. 